\title{
Rammed earth hygric properties and evolution
}

\author{
Margaux L. Indekeu ${ }^{1,}$, Chi Feng ${ }^{2}$, Hans Janssen ${ }^{2}$, and Monika Woloszyn ${ }^{1}$ \\ ${ }^{1}$ Université Savoie Mont Blanc, LOCIE, 73370 Le Bourget-du-Lac, France \\ ${ }^{2}$ KU Leuven, Department of Civil Engineering, Building Physics Section, 3001 Leuven, Belgium
}

\begin{abstract}
The hygric characterisation of authentic rammed earth materials is presented. Since these materials expand and liquefy upon contact with moisture, currently available methods are adapted to deal with this material evolution during the tests. In particular a thin permeable wick is introduced in the capillary absorption test. Moreover, confined and unconfined ways of testing are addressed. The results show that both the material origin and the material evolution can significantly impact the hygric properties.
\end{abstract}

\section{Introduction}

To assess the possibility of insulating rammed earth walls by computer simulation, reliable material properties are needed as input data. However, a literature study shows that there is a lack of formal knowledge on rammed earth material properties in three ways. Firstly, the materials used in the past studies are mostly reproduced in the lab, and therefore not necessarily representative for the authentic material. Secondly, the available material characteristics are incomplete: especially the moisture permeability in the overhygroscopic range is typically missing. Thirdly, the impact of the material evolution - expansion and liquefaction upon contact with moisture - on the moisture transfer properties remains hitherto unaddressed.

Hence, the objective is to perform a complete hygric characterisation for a few carefully selected rammed earth materials, with proper attention for the impact of material evolution. Further, the quality of the determined hygric properties is to be evaluated by an independent drying measurement and simulation for each material data set. Finally, a characteristic set of rammed earth materials is to be chosen based on the differences between the materials.

For this, several rammed earth building materials are collected on site for a material characterisation study in the lab. Firstly, basic information on the material structure and water stability is gathered, mainly by means of porosimetry. From this, the development of the strategy for determining the impact of the material evolution on the hygric properties follows, which involves confined (reference), unconfined, and repeated testing. Next, the moisture storage and transport properties are determined by means of a combination of desiccator tests, psychrometry and porosimetry for storage, and cup tests and capillary absorption testing for transport, respectively. Lastly, the determined hygric properties' representativeness for the respective materials' behaviour is verified by comparing drying test measurement and simulation results.

* Corresponding author: margaux.indekeu@live.be 


\section{Material information}

The investigated rammed earth materials are extracted from existing constructions at six different locations in the Auvergne-Rhône-Alpes region of France. In this way, a set of rammed earth materials which are considered to be representative for the main target building stock is obtained. The material of houses 2 to 6 is used directly; the earth of house 1 (H1) on the other hand is crushed, to then be reproduced in the lab via pressing or ramming $(\mathrm{P} / \mathrm{R})$.

A small capillary absorption test is performed to evaluate the materials' water stability. For this, a wick is introduced; otherwise the materials liquefy upon contact with water. Resultantly, differences in the $1 \mathrm{D}$ strain at capillary saturation ranging from $0.5 \%(\mathrm{H} 6)$ to $10 \%(\mathrm{H} 1 \mathrm{P})$ are observed. Part of this strain is irreversible upon drying, implying that the material structure has modified relative to the original one. Fig. 6a in Appendix shows mercury porosimetry results for the dry H1P material before (original) and after this water stability test. It is shown that, while the matrix density is constant, the porosity increases and the pores widen consequent to the unconfined absorption. On the other hand, the material remains unaffected when a confining sealing is applied during the water uptake and drying.

Fig. 1 (and 6b-d) shows the average porosimetry result for \pm three samples per (original) material. Based hereon, and considering availability, homogeneity, and originality aspects, $\mathrm{H} 1 \mathrm{P}, \mathrm{H} 2$, and $\mathrm{H} 6$ are preselected to be studied further, and H1R for the material evolution impact. Table 1 in Appendix collects some fundamental properties of these materials.

\section{Hygric property measurements}

\subsection{Moisture storage}

The absorption isotherm is measured, unconfined, by $11 \%, 33 \%, 53 \%, 75 \%$ - also confined $-, 85 \%, 94 \%$, and $97 \%$ relative humidity (RH) desiccators at $23.4^{\circ} \mathrm{C}$. For H1R (and H3-5), only the $33 \%, 75 \%$, and $97 \%$ RH data are gathered. Fig. 1 (and $6 \mathrm{~b}-\mathrm{d}$ ) includes the resulting averages of three samples per material. Relatively, three groups are distinguished: hygroscopic (H1), non-hygroscopic (H4, H5), and capillary-hygroscopic (H2) materials which start to fill remarkably at high RH. H3 and H6 are partly non-, partly capillaryhygroscopic, depending on the sample; the H6 stock used further is found non-hygroscopic.

The main wetting moisture retention curve in the overhygroscopic range is measured by psychrometry [1] with initially dry samples above water. The results in Fig. 1 show that especially for the capillary-hygroscopic material, the moisture retention can significantly exceed the porosimetry indications. Provisionally, the porosimetry curves are retained, cut off at the confined capillary moisture content and fitted by van Genuchten forms. For the unconfined H1R moisture retention curve, it is assumed that the modified - can be used.
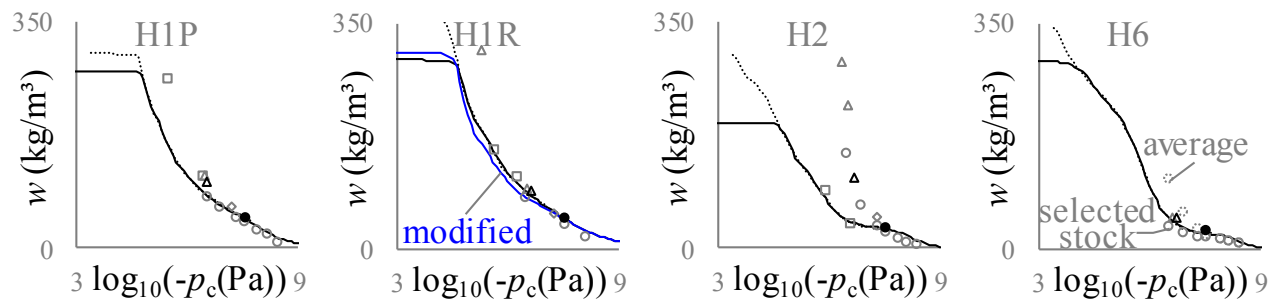

Fig. 1. Moisture retention test results: $\cdots$ mercury porosimetry, $\bullet$ desiccator tests, $\square \diamond \Delta$ psychrometry, fitting; black/grey markers indicate confined/unconfined testing; filled marker supplements porosity. 


\subsection{Moisture transport}

\subsubsection{Equivalent vapour permeability}

The moisture permeability in the hygroscopic range is measured by cup tests for $11 \%-53 \%$, $53 \%-84 \%$ and $84 \%-94 \% \mathrm{RH}$ at $\pm 24.6^{\circ} \mathrm{C}$ with initially dry samples. The results are included in Fig. 4 (and 8). The dry cup vapour resistance factor amounts to 11 for H1P and H2, 8 for $\mathrm{H} 1 \mathrm{R}$ and $\mathrm{H} 6$, and 6 for $\mathrm{H}_{1} \mathrm{R}_{\text {mod. }}$ The wet cup results are influenced by moisture islands.

\subsubsection{Capillary absorption}

The capillary absorption test in this work forms especially the basis for determining the moisture permeability, and hence most of the samples are X-ray formatted: $1.4 \mathrm{~cm}$ thick, $6.4 \mathrm{~cm}$ wide, and $6 \mathrm{~cm}$ high; the H1R samples are $9 \mathrm{~cm}$ high. As discussed, the material unstability leads to the test setup developments of the wick addition and the confining sealing application (Fig. 2a right). Hence, like the sample, the filter paper and the wick $(1 \mathrm{~cm}$ high, $0.5 \mathrm{~cm}$ immersed) are applied initially dry. The results in Fig. $2 \mathrm{~b}$ show that the wick and the accompanying interface cause an initial delay before the target sample's original absorption behaviour is retrieved [2]. As correction, a fictitious time is introduced (1), wherein the delay time, $t_{\mathrm{del}}^{0.5}$, is determined by the intersection of the first stage fitting with the $t^{0.5}$ axis.

$$
t_{\text {cor }}^{0.5}=t^{0.5}-t_{\text {del }}^{0.5}
$$

At least two samples per material are tested; only one is shown in Fig. 3 when the results are similar. The materials have ideal capillary absorption patterns [3]. Rounded, the capillary absorption coefficient amounts to $0.1 \mathrm{~kg} /\left(\mathrm{m}^{2} \mathrm{~s}^{0.5}\right)$ for $\mathrm{H} 1 \mathrm{P}$ and $\mathrm{H} 2,0.2 \mathrm{~kg} /\left(\mathrm{m}^{2} \mathrm{~s}^{0.5}\right)$ for $\mathrm{H} 6$, and $0.3 \mathrm{~kg} /\left(\mathrm{m}^{2} \mathrm{~s}^{0.5}\right)$ for H1R; the capillary moisture content to $200 \mathrm{~kg} / \mathrm{m}^{3}$ for $\mathrm{H} 2$ and $300 \mathrm{~kg} / \mathrm{m}^{3}$ for $\mathrm{H} 1$ and $\mathrm{H} 6$. Unconfined, the material swelling gives a $37 \%$ capillary absorption coefficient (and about 50\% - moisture content -) increase for H1R. (The volume is unadjusted in the data processing for this, which is supported by the observation that most of the macroscopic swelling occurs after the moisture front reaches the top.) The impact on the resulting modified material properties (tested confined) is $+15 \%$ and $+4 \%$, respectively.

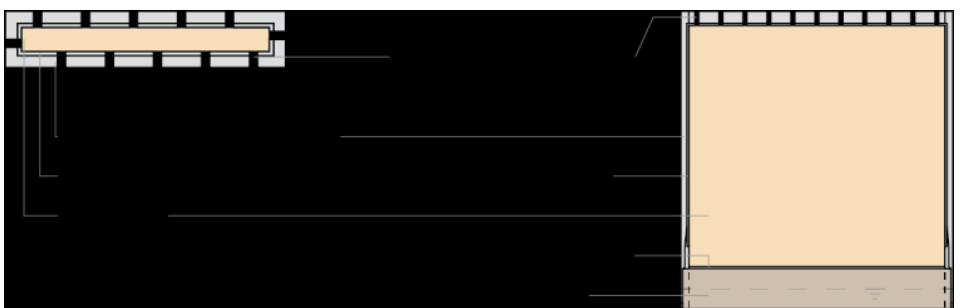

(a)

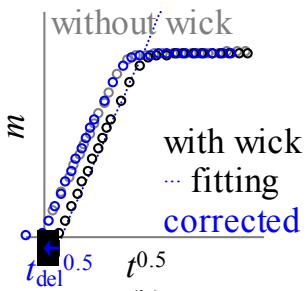

(b)

Fig. 2. (a) Confined test setups; (b) Demonstration of wick-correction method (ceramic brick sample).
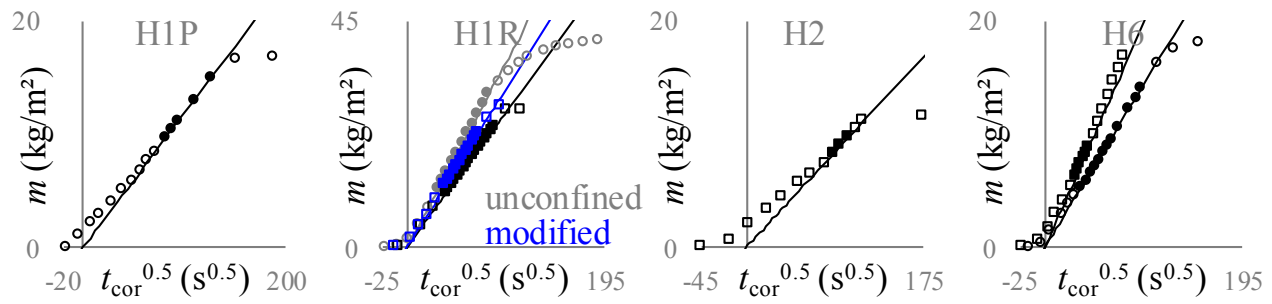

Fig. 3. Capillary absorption test results: $\circ$ lab $\left(22.3^{\circ} \mathrm{C}\right), \square \mathrm{X}$-ray $\left(25^{\circ} \mathrm{C}\right),-$ fitting; filled markers indicate the data used for the fitting and selected for the Boltzmann profile (Fig. 7) where applicable. 


\subsubsection{Moisture diffusivity}

The moisture diffusivity is determined with the aim of obtaining the moisture permeability. The theoretical background for its experimental determination follows from the moisture mass conservation equation, formulated with the moisture diffusivity describing the moisture transport using the moisture content as the governing variable. Hence, the Boltzmann-conditions fulfilled [4a], the transformation of the transient moisture content profiles measured during the capillary absorption test by (2) delivers the diffusivity as (3). For more information on the experimental procedure and the data processing method for the quantification of the moisture content profiles, see [5] and [6], which are followed largely.

$$
\begin{gathered}
\lambda_{\text {cor }}=x / t_{\text {cor }}{ }^{0.5} \\
D_{\mathrm{m}}=-1 / 2 \int_{\mathrm{w} 0}{ }^{\mathrm{w}} \lambda_{\text {cor }} \mathrm{d} w /\left(\mathrm{d} w / \mathrm{d} \lambda_{\text {cor }}\right)
\end{gathered}
$$

The selection of the resulting transformed moisture content profiles captured in Fig. 7 in Appendix demonstrates the validity of the above outlined determination method for each of the investigated materials. One characteristic profile is kept and approximated smoothly using cubic spline interpolation to facilitate the derivation [4b]. Fig. 8 in Appendix shows the corresponding obtained moisture diffusivity, supplemented by integration of the cup test results. The capillary absorption test simulation (not shown) with the determined properties is already correct for $\mathrm{H} 1 \mathrm{R}$ and $\mathrm{H} 6$; but for $\mathrm{H} 1 \mathrm{P}$ and $\mathrm{H} 2$, it results in an overestimation of $A_{\mathrm{c}}$.

\subsubsection{Moisture permeability}

The moisture permeability is obtained by the product of the moisture diffusivity and the moisture capacity (4). This transport property is a function of the capillary pressure, which is the moisture transfer potential to be used in the numerical simulations. Since moisture transport consists of liquid water and water vapour in parallel, the moisture permeability can be described as the sum of the liquid- and the vapour permeability (this separation is fictional, but required in the modelling). Herein, the vapour permeability is calculated using a bundle-of-tubes approach (5), based on the moisture retention curve and the dry cup data.

$$
\begin{gathered}
k_{\mathrm{m}}=D_{\mathrm{m}} \partial w / \partial p_{\mathrm{c}} \\
k_{\mathrm{v}}=\delta_{\text {air }} / \mu\left(1-w / w_{\text {sat }}\right) p_{\mathrm{v}, \mathrm{sat}} \exp \left(p_{\mathrm{c}} /\left(\rho_{\text {wat }} R_{\mathrm{v}} T\right)\right) /\left(\rho_{\text {wat }} R_{\mathrm{v}} T\right)
\end{gathered}
$$

Fig. 4 collects the resulting moisture transport properties. The mean moisture permeability in the high steep end reflects the capillary absorption coefficient trend for the different materials. The material swelling during the unconfined capillary absorption test leads to an increase of this moisture permeability; cf. the swelling occurs in and thus impacts only the wet part of the material. The modified material afterwards has wider pores and an increased porosity, which results in an increased wet and dry moisture permeability.
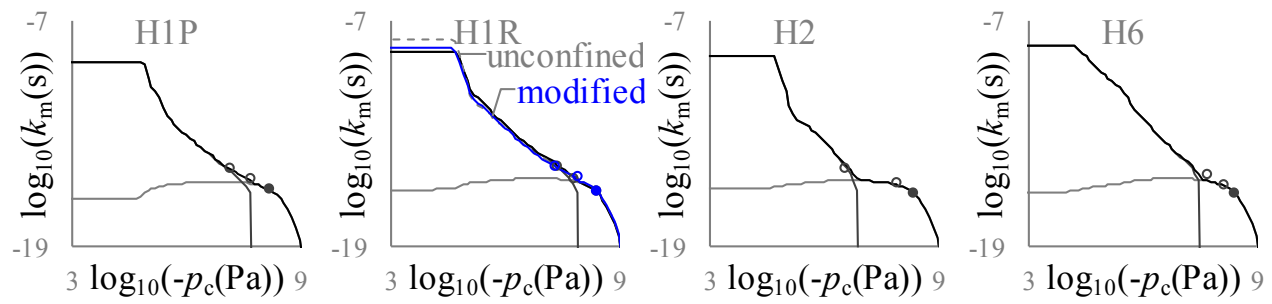

Fig. 4. Moisture permeability for the different rammed earth materials: $-k_{\mathrm{m}},-k_{\mathrm{l}},-k_{\mathrm{v}}, \bullet \circ$ cup tests. 


\section{Drying simulations}

The drying test is performed subsequent to the capillary absorption test. For this, the samples (cf. Fig. 2a right) are turned upside down, the perforations sealed with vapour tight tape, and all sides but the ceramic brick face thermally insulated with extruded polystyrene. The conditions during the test are $\pm 55 \% \mathrm{RH}, 23.4^{\circ} \mathrm{C}$, and maximum $4 \mathrm{~m} / \mathrm{s}$ airflow velocity.

In the simulation of the test with DELPHIN software, 1D heat and moisture transfer are taken into account. For the thermal conductivity as a linear function of the moisture content and the heat capacity, $0.5 \mathrm{~W} /(\mathrm{mK})$ dry to $1.2 \mathrm{~W} /(\mathrm{mK})$ saturated and $900 \mathrm{~J} /(\mathrm{kgK})$ are assumed, resp., both for the ceramic brick and the rammed earth materials. The ceramic brick hygric properties are determined cf. the above methods. The convective surface moisture transfer coefficient is taken $1.25 \times 10^{-7} \mathrm{~s} / \mathrm{m}$ to reproduce the first drying period rate. Fig. 5 shows the measurement and simulation results. The bad agreement between the results indicates that the material properties need to be adjusted, with proper attention for the intermediate moisture permeability. This applies in the first instance to the ceramic brick wick material, for which the simulated second drying period is already incorrect as well (not shown).
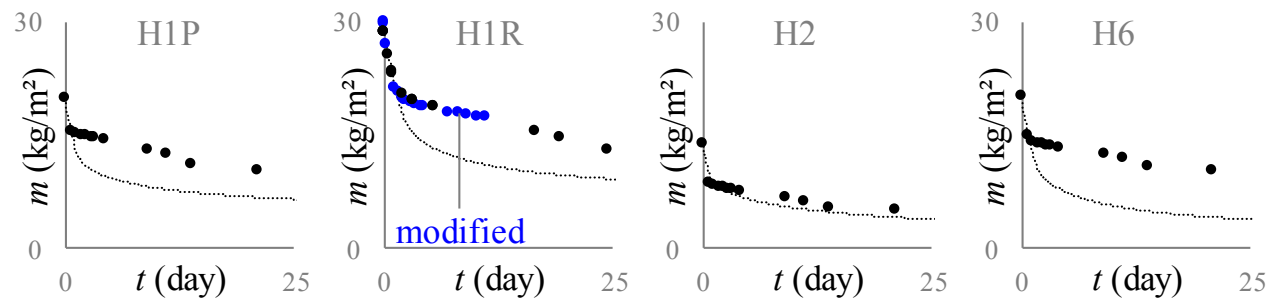

Fig. 5. Drying tests for the different rammed earth materials: • measurement, $\cdots$ simulation.

\section{Conclusion}

In the hygric characterisation of rammed earth materials, the coupling with the mechanical behaviour plays a role: the material expansion and partial re-contraction upon moistening and drying respectively, can significantly affect the moisture transfer properties. Hence, for a consistent reference characterisation, a confining sealing is applied which limits the swelling during the hygric tests. Complementary, for the material evolution impact, the properties are also measured in an unconfined way, and the modified material properties after unconfined wetting up to the capillary saturation state and re-drying are determined as well.

By the reference tests, it is found that the studied materials differ qua moisture storage capacity from relatively non-hygroscopic for $\mathrm{H} 6$ to hygroscopic for $\mathrm{H} 1$; and, regarding the capillary moisture content, $\mathrm{H} 2$ can buffer only $2 / 3$ of the amount of moisture as compared to the other materials. Qua moisture transport, H1P and H2 are less vapour permeable than and absorb water twice as difficult and slow as H1R; and H6 performs in between.

Unconfined, the materials change under the influence of moisture, of which the impact on the hygric properties is studied for the moderately-expansive and homogenous H1R material. Hence, it is found that the hygroscopicity decreases, and the moisture capacity and permeability near capillary saturation increase during unconfined moistening. The modified material - re-dried (and confined) - after this, has wider pores, which leads to an increased wet and dry moisture permeability and a reduced intermediate moisture transfer.

Although the material property functions need yet to be calibrated, the characteristic variations observed in the basic measurements show already that a diverse set of rammed earth materials is obtained. Therefore, different rammed earth wall materials can be considered in an insulatability analysis in order to allow comprehensive conclusions. Moreover, the hygromechanical behaviour impact on the performance can be addressed. 
This project is supported by the Auvergne-Rhône-Alpes region, France.

\section{References}

[1] C. Feng, \& H. Janssen (2019). Bld. and Env., (Iv).

[2] M. A. Wilson, W. D. Hoff, \& C. Hall (1995). Bld. and Env., 30(2), 209-219.

[3] C. Feng, \& H. Janssen (2018). Bld. and Env., 134(January), 21-34.

[4] (a) S. Roels, et al. (2004). J. of Bld. Phys., 27(4), 261-276.; (b) idem, 277-305.

[5] S. Roels, \& J. Carmeliet (2006). Int. J. of Heat and Mass Tfr., 49(25-26), 4762-4772.

[6] B. J. Pease, G. A. Scheffler, \& H. Janssen (2012). Constr. and Bld. Mat., 36, 419-429.

\section{Appendix}

Table 1. Basic properties of the different rammed earth materials.

\begin{tabular}{cccccccc}
\hline material $\varepsilon_{\text {cap }}(\mathrm{m} / \mathrm{m}, \%)^{\mathrm{a}} \rho_{\text {bul }}\left(\mathrm{kg} / \mathrm{m}^{3}\right)^{\mathrm{b}} \psi_{\mathrm{o}}\left(\mathrm{m}^{3} / \mathrm{m}^{3}, \%\right)$ & $w_{75 \%}\left(\mathrm{~kg} / \mathrm{m}^{3}\right)$ & $\mu_{\text {dry }}(-)$ & $w_{\text {cap }}\left(\mathrm{kg} / \mathrm{m}^{3}\right) A_{\mathrm{c}}\left(\mathrm{kg} /\left(\mathrm{m}^{2} \mathrm{~s}^{0.5}\right)\right)^{\mathrm{c}}$ \\
\hline H1P & 10 & 1901 & 30 & $45 \mid 40^{\mathrm{a}}$ & 11 & 274 & 0.116 \\
$\mathrm{H}^{\mathrm{P}}{ }_{\text {mod }}$ & $/$ & 1737 & 36 & $45^{\mathrm{d}}$ & $/$ & $/$ & $/$ \\
H1R & 7 & 1752 & 37 & $45 \mid 35^{\mathrm{a}}$ & 8 & $293 \mid 440^{\mathrm{a}, \mathrm{e}}$ & $0.267 \mid 0.367^{\mathrm{a}}$ \\
$\mathrm{H}_{1} \mathrm{R}_{\text {mod }}$ & $/$ & 1675 & 39 & $45^{\mathrm{d}} \mid 35^{\mathrm{a}}$ & 6 & 304 & 0.300 \\
H2 & 5 & 1860 & 30 & $31 \mid 25^{\mathrm{a}}$ & 11 & $195 \mid 248^{\mathrm{a}, \mathrm{e}}$ & 0.092 \\
$\mathrm{H} 6$ & 0.5 & 1708 & 34 & $24 \mid 15^{\mathrm{a}}$ & 8 & $291 \mid 298^{\mathrm{a}, \mathrm{e}}$ & 0.169 \\
\hline
\end{tabular}

a unconfined; ${ }^{\mathrm{b}} 70^{\circ} \mathrm{C}$ oven drying method; ${ }^{\mathrm{c}}$ recalculated for $20^{\circ} \mathrm{C} ;{ }^{\mathrm{d}}$ assumption; ${ }^{\mathrm{e}}$ estimation.

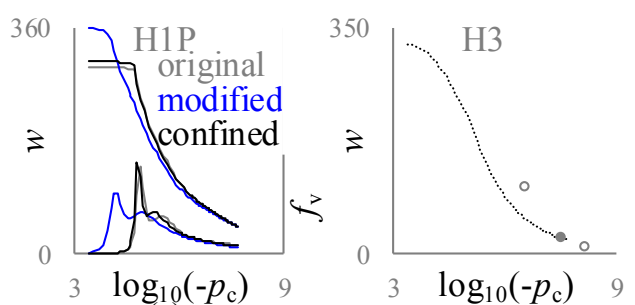

(a)

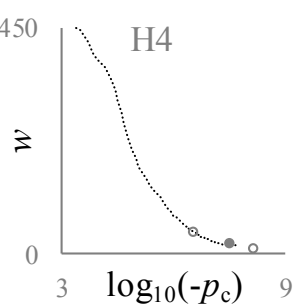

(c)

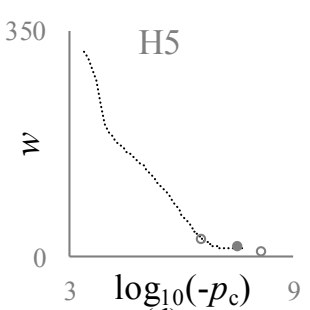

(d)

Fig. 6. (a) Water stability porosimetry; (b-d) Moisture retention results: $\cdots$ porosimetry, $\bullet$ desiccators.
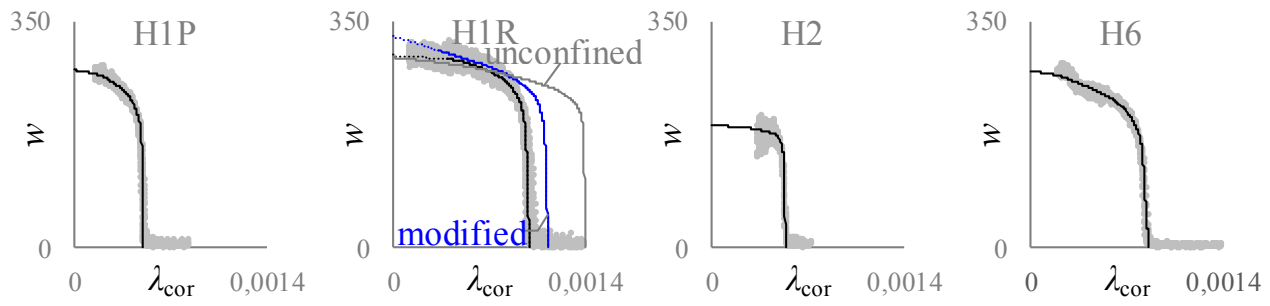

Fig. 7. Boltzmann transformed moisture content profiles for the different rammed earth materials.
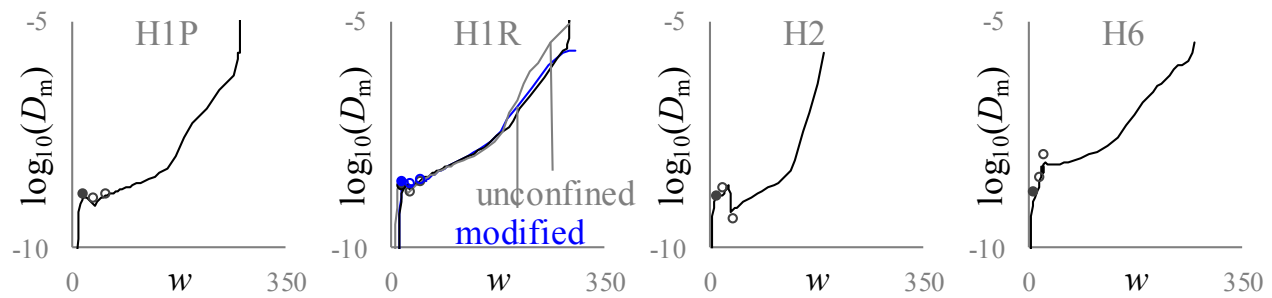

Fig. 8. Moisture diffusivity for the different rammed earth materials with cup test results integrated. 